\title{
Primary Lymph Node Gastrinoma or Metastatic Gastrinoma with Unidentified Primary Tumor Site?
}

\author{
Jack L Martin, Michele Tedeschi, James E Jackson, Duncan Spalding, Anthony P Goldstone \\ Patrizia Cohen, Andrea Frilling
}

\begin{abstract}
Gastrinomas are neuroendocrine tumors that secrete gastrin and result in a clinical syndrome of peptic ulcer disease first described by Zollinger and Ellison in $1955 .{ }^{1}$ They present either sporadically or as a component of a hereditary determined syndrome, multiple endocrine neoplasia type 1 . They are usually located in the pancreas and duodenum but have been reported to occur in both abdominal and extraabdominal sites. ${ }^{2}$ Reports of clinical and biochemical cure following resection of lymph nodes found to contain gastrinomas, in patients without a localized primary tumor, led investigators to cite the existence of the primary lymph node gastrinoma. Whether these cases represent metastatic disease from an, as yet, unidentified primary tumor, or de novo occurrence of a gastrinoma in a lymph node remains controversial. While some authors report that primary lymph node gastrinomas account for up to $10 \%$ of sporadic gastrinomas ${ }^{3,4}$ others question this theory, hypothesizing that their presentation represents an undetected microgastrinoma with metastatic lymph node involvement. ${ }^{5}$

Herewith, we report on a patient with Zollinger-Ellison syndrome in whom a peripancreatic lymph node with evidence of gastrinoma is the only apparent morphologic manifestation of the disease.
\end{abstract}

Keywords: Zollinger-Ellison syndrome, Metastasized gastrinoma, Primary lymph node gastrinoma.

How to cite this article: Martin JL, Tedeschi M, Jackson JE, Spalding D, Goldstone AP, Cohen P, Frilling A. Primary Lymph Node Gastrinoma or Metastatic Gastrinoma with Unidentified Primary Tumor Site? World J Endocr Surg 2012;4(2):66-70.

Source of support: Nil

Conflict of interest: None declared

\section{CASE REPORT}

A 42-year-old male initially presented to his local hospital in 1999 with nausea, vomiting, weight loss and reflux symptoms including, upper abdominal pain and bloating. Apart from asthma he had no other past medical history. His parents had essential hypertension but there was no family history of Zolliger-ellison syndrome (ZES) or multiple endocrine neoplasia type 1 (MEN 1)-associated symptoms.

Esophagogastroduodenoscopy (OGD) demonstrated multiple duodenal ulcers. Treatment with proton pump inhibitors (PPI) and antibiotic eradication of Helicobacter pylori was initiated. Following further investigation, the patient was diagnosed with ZES but magnetic resonance imaging (MRI) and computed tomography (CT) performed in 2002 both failed to identify a tumor. Subsequent endoscopic ultrasound (EUS) revealed no pathologic findings. He continued to experience profound nausea and vomiting with frequent episodes of diarrhea although his weight remained stable.

In 2007, he was referred to another institution for consideration of further investigation to attempt to identify an underlying gastrinoma. Although on PPIs, he still suffered periods of severe abdominal pain with diarrhea preventing him from leaving the house for days. Bloods demonstrated an elevated fasting plasma gastrin of $195 \mathrm{pmol} / \mathrm{l}$ (normal <40 pmol/l) with normal fasting glucagon, vasointestinal peptide, pancreatic polypeptide and chromogranin A and B. Gastric acid studies revealed an elevated basal gastric acid production of $95 \mathrm{mmol} / \mathrm{h}$ (normal $<10 \mathrm{mmol} / \mathrm{h}$ ).

EUS demonstrated moderate erosive esophagitis and severe erosive duodenitis. A thickened duodenal wall with several small periduodenal lymph nodes was present but no other lesion could be visualized.

A repeat EUS in 2010 revealed a $5 \times 8 \mathrm{~mm}$ hypoechoic mass localized within the prepyloric region and several periduodenal lymph nodes that appeared inflammatory in nature. On $\mathrm{CT}$, a $7 \mathrm{~mm}$ enhancing nodule medial to the second part of the duodenum became evident (Fig. 1). Three, subcentimeter lesions in the liver were consistent with simple cysts. An Octreoscan (229 MBq 111 indium octreotide) revealed no pathologic uptake. Mesenteric

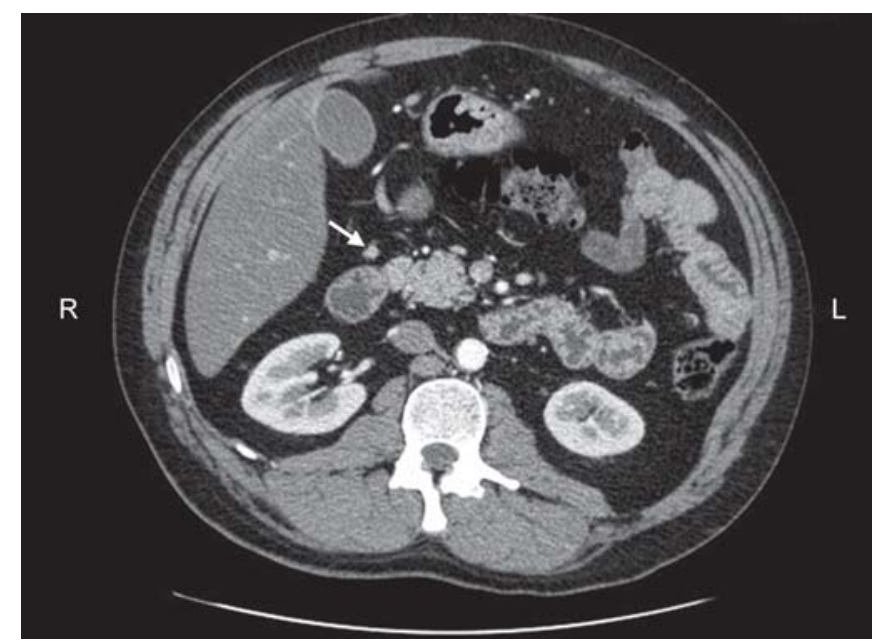

Fig. 1: Axial section from a contrast CT abdomen demonstrating a $7 \mathrm{~mm}$ lesion (arrow) adjacent to the second part of the duodenum 
angiography showed an $8 \mathrm{~mm}$ region of increased vascularity over the medial aspect of the second part of the duodenum consistent with the enhancing nodule seen on CT (Fig. 2). A gastrin stimulation test with calcium disclosed an isolated 10-fold peak within the gastroduodenal artery. In contrast to Octreoscan, 68Ga-Dotatate positron emission tomography (PET) confirmed an avid lesion adjacent to the second part of the duodenum corresponding with the nodule seen on CT (Fig. 3). His fasting plasma gastrin at this time was $290 \mathrm{pmol} / \mathrm{l}$ (normal <40 pmol/l).

Normal serum concentration of parathyroid hormone, vitamin $\mathrm{D}$ and prolactin with corrected calcium of $2.10 \mathrm{mmol} / \mathrm{l}$, and a urinary 5-hydroxyindoleacetic acid (HIAA) was noted. Compared to the results from 2007, chromogranin A was elevated at 90 pmol/l (range, 0-60).

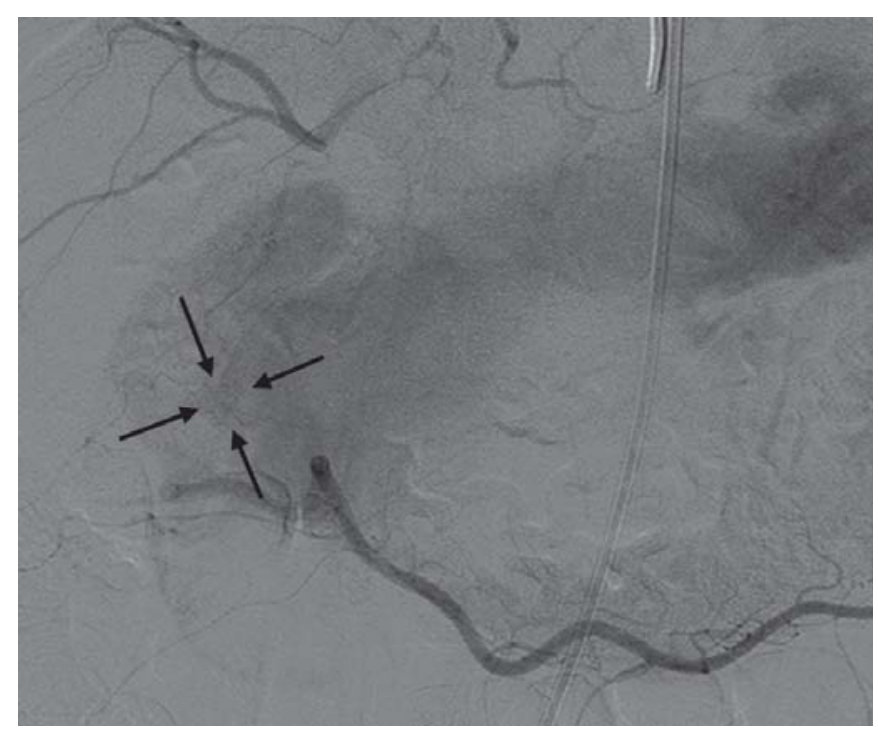

Fig. 2: Selective celiac axis angiography demonstrating a welldefined nodule of faintly increased vascularity measuring approximately $8 \mathrm{~mm}$ in maximal diameter and superimposed on the medial aspect of the second part of the duodenum (arrows)

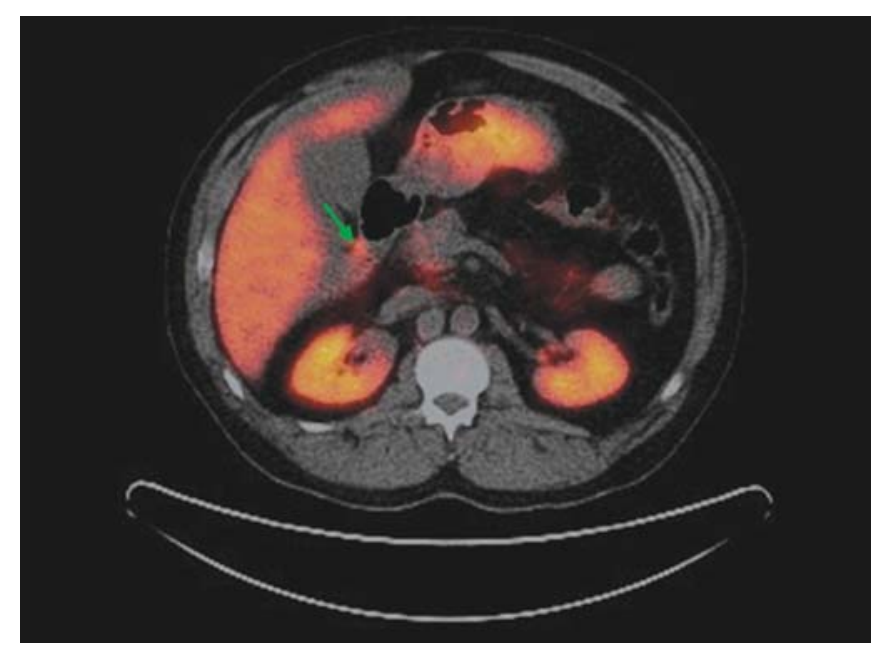

Fig. 3: Axial section from 68Ga Dotatate PET demonstrating a Dotatate avid lesion adjacent to the second part of the duodenum (arrow)
Genetic screening for MEN 1 mutations was negative. The patient was subsequently found to have severe hypertension (172/108 mm Hg), episodes of migraine and episodes of rectal bleeding associated with hemorrhoids. Further investigation with regard to hypertension was unremarkable with normal electrolytes, a normal echocardiogram, normal imaging of his kidneys and adrenals, normal autoimmune screen, bicarbonate, 24 hours urinary collections for catecholamines and metanephrines and appropriate suppression of cortisol on low-dose dexamethasone suppression test. A diagnosis of essential hypertension was made and appropriate medical therapy initiated. During this period, he reported a significant gain in weight from $72.9 \mathrm{Kg}$ at the time of investigation in March 2008 to 85.2 Kg in May 2010 at the time of surgery.

Finally, in June 2010, the patient underwent laparotomy. Corresponding with the imaging results an $8 \mathrm{~mm}$, wellencapsulated, firm tumor anterior to the pyloric region embedded in fatty tissue was found. Meticulous exploration of the upper abdomen, including manual duodenal exploration and sonography of the liver and pancreas, revealed no other pathological findings apart from advanced hepatosteatosis. Systematic lymphadenectomy, including the prepyloric tumor, within the gastrinoma triangle was performed. The postoperative course was uneventful and the patient was discharged on the eight postoperative day.

Histological examination of the prepyloric tumor disclosed a single lymph node measuring $9 \mathrm{~mm}$ in maximum diameter almost completely replaced by tumor with appearances consistent with a neuroendocrine tumor (Fig. 4). No mitoses were seen in a 10 high-power field and no extracapsular spread was evident. On immunohistochemistry, the tumor was diffusely positive for gastrin and

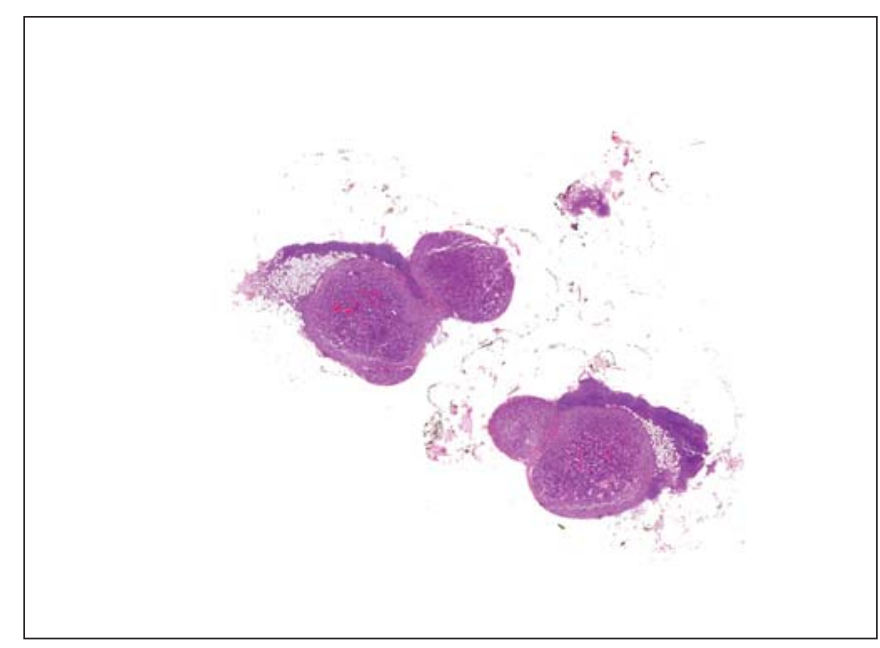

Fig. 4: Bisected lymph node almost completely replaced by a neuroendocrine tumor. $\mathrm{H}$ and $\mathrm{E} 10 \times$ 
synaptophysin and focally positive for chromogranin. Stainings for somatostatin, serotonin and glucagon were weakly positive (Figs 5 and 6). The Ki-67 proliferation index was $<2 \%$. The diagnosis of a well-differentiated, low-grade, neuroendocrine tumor (NET) was made. A further seven lymph nodes had no evidence of tumor.

At a follow-up 7 weeks postoperatively, the patient was asymptomatic in a significantly improved general condition. He had lost $3.5 \mathrm{Kg}$ in weight. At the last follow-up performed 21 months after surgery the patient remained asymptomatic. Gut hormone studies at this time demonstrated a normal fasting plasma gastrin (32 pmol/l) and chromogranin A (42 pmol/l; Table 1).

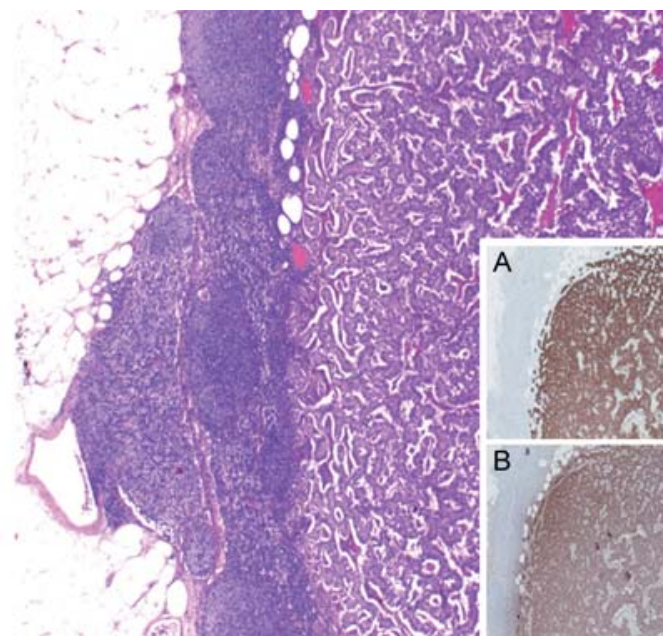

Figs 5A and B: Neuroendocrine tumor with a trabecular growth pattern (right) and rim of preserved lymph node tissue (left). $\mathrm{H}$ and E 100× (A) neuroendocrine tumor showing strong and diffuse synaptophysin expression. Immunostain $100 \times$ (B) neuroendocrine tumor showing diffuse expression for gastrin. Immunostain 100x

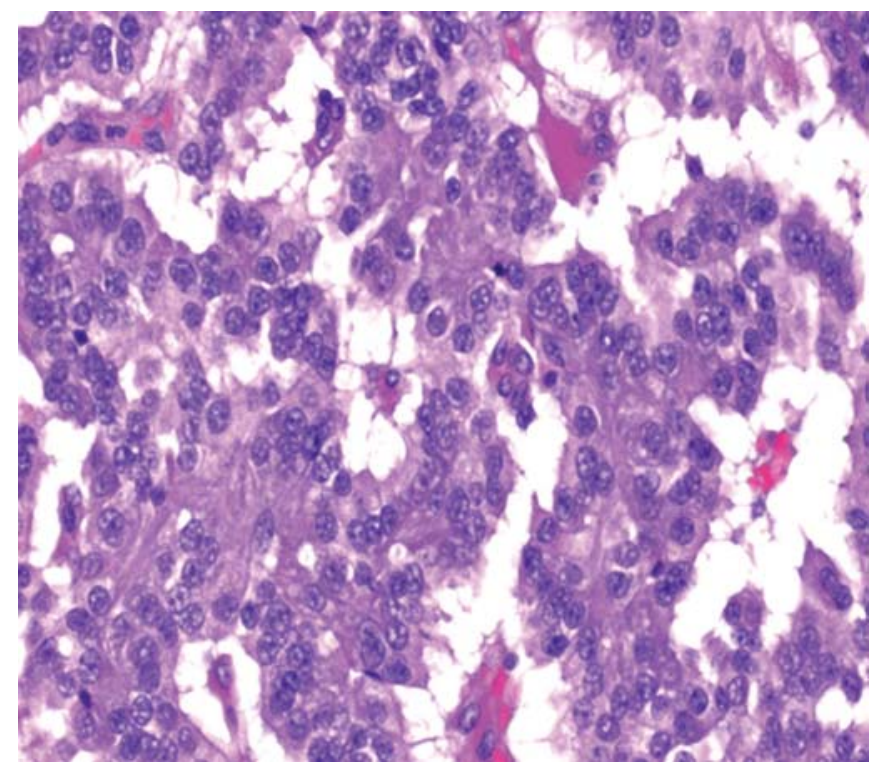

Fig. 6: Higher magnification showing trabeculae of polygonal cells with uniform round nuclei with stippled chromatin and small nucleoli $\mathrm{H}$ and $\mathrm{E} 400 \times$

\begin{tabular}{|c|c|c|c|}
\hline & $\begin{array}{c}\text { Pre- } \\
\text { operative }\end{array}$ & $\begin{array}{c}\text { Post- } \\
\text { operative } \\
\text { (21 months } \\
\text { follow-up) }\end{array}$ & $\begin{array}{l}\text { Normal } \\
\text { range }\end{array}$ \\
\hline Chromogranin A & 90 & 42 & $<60 \mathrm{pmol} / \mathrm{l}$ \\
\hline Gastrin & 290 & 32 & $<40 \mathrm{pmol} / \mathrm{l}$ \\
\hline Chromogranin B & 86 & 85 & $<150 \mathrm{pmol} / \mathrm{l}$ \\
\hline $\begin{array}{l}\text { Pancreatic } \\
\text { Polypeptide }\end{array}$ & 28 & 36 & $<300 \mathrm{pmol} / \mathrm{l}$ \\
\hline VIP & 4 & 3 & $<30 \mathrm{pmol} / \mathrm{l}$ \\
\hline Somatostatin & 82 & 59 & $<150 \mathrm{pmol} / \mathrm{l}$ \\
\hline Glucagon & $<5$ & 6 & $<50 \mathrm{pmol} / \mathrm{l}$ \\
\hline
\end{tabular}

\section{DISCUSSION}

The existence of primary lymph node gastrinomas remains contentious. A report by Norton et al suggested that $10 \%(13 / 138$ in this series) of all patients with sporadic ZES had a lymph node primary and remained cured following lymphadenectomy at long-term follow-up (10.4 \pm 1.2 years). ${ }^{3}$ These findings were supported by a study by Arnold et al who found that in his experience 8\% of patients (9/110) who underwent surgical exploration for ZES were found to have disease limited to one or more lymph nodes and remained biochemically cured at a median follow-up of 5.3 years. ${ }^{6}$

The majority of gastrinomas arise in the duodenum and pancreas. Those arising from the duodenum account for $70 \%$ and develop from $\mathrm{G}$ cells. Since, these cells are not found in the adult pancreas, an alternative model of tumorgenesis for gastrinomas of the pancreas has been suggested. This concept finds support in the pathophysiological differences in their malignant potential. ${ }^{7}$ Pancreatic islet cells are thought to arise from pancreatic stem cells that are found at the tip of the developing pancreatic ductule. In 1984, Stabile et al observed that the majority of gastrinomas were located in a region consecutively recognized as the 'gastrinoma triangle. ${ }^{8}$ It was hypothesized that this region corresponded to an area of pancreatic development, where the ventral pancreatic bud rotates through $180^{\circ}$ around the primitive foregut. Primary lymph node gastrinomas were thought to arise from such pancreatic stem cells that had failed to migrate and had subsequently been incorporated within lymph nodes in this area. ${ }^{8,9}$

Opponents to the existence of primary lymph node gastrinomas cite reports of microgastrinomas in the duodenum that are easily overlooked and the observation that even these small tumors have been shown to give rise to extensive metastatic disease. Anlauf et al demonstrated the existence of multiple primary microgastrinomas ( 0.45 and $0.8 \mathrm{~mm}$ ) in a MEN 1 patient only after complete embedding of a total pancreaticoduodenectomy specimen. ${ }^{5}$ The conventional histopathological investigation had only found 
gastrinoma within suprapancreatic lymph nodes. The observation that primary duodenal gastrinomas were considerably more common (70-100\% in MEN 1 patients and 50 to $88 \%$ in sporadic patients) than previously quoted $(<20 \%)$ further strengthened this argument. ${ }^{2}$ MEN 1associated gastrinoma is present in only 20 to $30 \%$ of ZES patients, however, and sporadic gastrinomas have clear differences in their presentation, distribution and prognosis. ${ }^{10}$

In MEN 1, the primary tumors are multifocal and almost always $(70-100 \%)$ located in the duodenum, originating directly from $G$ cells. ${ }^{2,7}$ In the series of Norton et al advocating the existence of primary lymph node gastrinomas, disease relapse occurred in $31 \%$ of patients (8/26; range, 2-10 years) who experienced an initial 'diseasefree period.' This cohort included both, sporadic and MEN 1 ZES patients. In the patients with sporadic ZES, a primary duodenal tumor was first detected at second exploration in three of them. ${ }^{3}$

As this case demonstrates, gastrinomas can prove to be a diagnostic conundrum.

The use of transabdominal ultrasound is limited due to the relatively low sensitivity in localizing small primary tumors within the pancreas and duodenum. Endoscopic ultrasound is effective in tumor localization within the pancreas and duodenum with reported sensitivities in the range 79 to $100 \%$ in expert hands. ${ }^{11}$ Initial studies of CT reported detection rates of only $28 \%{ }^{10}$ The significant improvements in spatial and temporal resolution and the use of multiphasic contrast-enhanced CT has resulted in a markedly improved sensitivity of up to $95 \%$ for tumors localized within the pancreas. ${ }^{11}$ For MRI, positive predictive values of $94 \%$ have been reported. ${ }^{11,12}$

Functional imaging, ideally in fusion with morphologic imaging, has a key role in the modern diagnosis, staging and follow-up of patients with NETs. Depending upon the tumor type, somatostatin receptor scintigraphy (Octreoscan) has a reported overall sensitivity of 80 to $90 \% .^{13}$ Developments in somatostatin analogues have enabled radiolabeling with positron emitting tracers (PETs) suitable for PET imaging in combination with CT (e.g. 68Ga-Dotatoc $\mathrm{PET} / \mathrm{CT}$ ) that has further improved the diagnostic accuracy. ${ }^{14}$ Detection of tumors less than $1 \mathrm{~cm}$ in size still remains challenging. ${ }^{11,12,15}$

An interesting observation in the patient presented in this report was the fluctuations of weight during the course of the disease. Following initial diagnosis, his weight steadily increased. After surgery he was then noted to return toward his presenting weight. Weight gain in ZES has been observed by Raoul et al in a cohort of 18 ZES patients. This cohort experienced weight loss at the time of diagnosis with a rebound weight gain following the commencement of treatment. They proposed two hypotheses for these observations. ${ }^{16}$ First, that ZES patients learnt to change their diet as frequent meals reduce their symptoms. Following their diagnosis and commencement of treatment, these continued dietary habits coupled with a reduction in fat malabsorption resulted in weight gain. The second, that weight gain might be a consequence of elevated gastrin levels which may cause desensitization of receptors to the hunger suppressant, cholecystokinin, with a resultant impaired control of satiety. ${ }^{16}$

Advocates of the existence of primary lymph node gastrinomas would suggest the case presented in this report may prove to support this theory. Nevertheless, the wellrecognized difficulty in localizing microgastrinomas and the short follow-up continue to suggest that this case represents another example of a metastatic gastrinoma with an, as yet, unidentified primary.

\section{ACKNOWLEDGMENT}

Professor Adil Al-Nahhas, Director of the Department for Nuclear Medicine, Imperial College London performed 68Ga Dotatate PET in this patient.

\section{REFERENCES}

1. Zollinger RM, Ellison EH. Primary peptic ulcerations of the jejunum associated with islet cell tumours of the pancreas. Ann Surg 1955;142:709-28.

2. Jensen RT, Niederle B, Mitry E, et al. Gastrinoma (Duodenal and pancreatic). Neuroendocrinology 2006;84:173-82.

3. Norton JA, Alexander RH, Fraker DL, et al. Possible primary lymph node gastrinoma: Occurrence, natural history and predictive factors. Ann Surg 2003;237:650-59.

4. Kitagawa M, Hayakawa T, Kondo T, et al. Gastrinoma in a mesenteric lymph node. Am J Gastroenterol 1989;84(6):660-62.

5. Anlauf M, Enosawa T, Henopp T, et al. Primary lymph node gastrinoma or occult duodenal microgastrinoma with lymph node metastases in a MEN1 patient. Am J Surg Pathol 2008;32: 1101-05.

6. Arnold WS, Fraker DL, Alexander HR, et al. Apparent lymph node primary gastrinoma. Surgery 1994;116(6):1123-29.

7. Schimmack S, Svejda B, Lawrence B, et al. The diversity and commonalities of neuroendocrine tumors. Langenbecks Arch Surg 2011;396:273-98.

8. Stabile BE, Morrow DJ, Passaro Jr E. The gastrinoma triangle: Operative implications. Ann Surg 1984;147:25-31.

9. Passaro Jr E, Howard TJ, Sawicki MP, et al. The origin of sporadic gastrinomas within the gastrinoma triangle. Arch Surg 1998;133:16-19.

10. Gibril F, Schumann M, Pace A, et al. Multiple endocrine neoplasia type 1 and Zollinger-Ellison syndrome: A prospective study of 107 cases and comparison with 1009 patients from the literature. Medicine 2004;83:43-83.

11. Rockall AG, Reznek RH. Imaging of neuroendocrine tumours (CT/MR/US). Best Pract Res Clin Endocrinol Metab 2007;21(1): 43-68.

12. Noone TC, Hosey J, Firat Z, Semelka RC. Imaging and localization of islet-cell tumours of the pancreas on CT and MRI. Best pract res clin. Endocrinol Metab 2005;19(2):195-211. 
13. Gabriel M, Decristoforo C, Kendler D, et al. 68Ga-DOTA-Tyr3octreotide PET in neuroendocrine tumors: Comparison with somatostatin receptor scintigraphy and CT. J Nucl Med 2007;48: 508-18.

14. Frilling A, Sotiropoulos GC, Radtke A, et al. The impact of 68Ga Dotatoc PET/CT on the multimodal management of patients with neuroendocrine tumours. Ann Surg 2010;252:850-56.

15. Elsayes KM, Menias CO, Bowerson M, et al. Imaging of carcinoid tumours: Spectrum of findings with pathologic and clinical correlation. J Comput Assist Tomogr 2011;35(1): 72-80.

16. Raoul JL, Bretagne JF, Ropert A, et al. Zollinger-Ellison syndrome, antisecretory treatment, and body weight. Dig Dis Sci 1992;37(8):1308-09.

\section{ABOUT THE AUTHORS}

\section{Jack L Martin}

Resident, Department of Surgery and Cancer, Imperial College Healthcare NHS Trust, Hammersmith Hospital, London United Kingdom

\section{Michele Tedeschi}

Resident, Department of Surgery and Cancer, Imperial College Healthcare NHS Trust, Hammersmith Hospital, London United Kingdom

\section{James E Jackson}

Consultant Radiologist, Department of Imaging, Imperial College Healthcare NHS Trust, Hammersmith Hospital, London United Kingdom

\section{Duncan Spalding}

Consultant Surgeon, Department of Surgery and Cancer, Imperial College Healthcare NHS Trust, Hammersmith Hospital, London United Kingdom

\section{Anthony P Goldstone}

Consultant Endocrinologist, Department of Imperial Centre for Endocrinology, Imperial College Healthcare NHS Trust Hammersmith Hospital, London, United Kingdom

\section{Patrizia Cohen}

Consultant Histopathologist, Department of Histopathology Imperial College Healthcare NHS Trust, Hammersmith Hospital London, United Kingdom

\section{Andrea Frilling (Corresponding Author)}

Professor, Department of Surgery and Cancer, Imperial College Healthcare NHS Trust, Hammersmith Hospital, London United Kingdom, e-mail: a.frilling@imperial.ac.uk 